\title{
Caracterização do regime de vento em superfície na Região Metropolitana do Rio de Janeiro
}

\author{
Characterization of surface wind regime in the Metropolitan Area of Rio de Janeiro
}

Luiz Cláudio Gomes Pimentel', Edilson Marton², Mauricio Soares da Silva ${ }^{3}$, Pedro Jourdan ${ }^{4}$

\begin{abstract}
RESUMO
O trabalho aborda a caracterização do regime de vento em diversos setores da Região Metropolitana do Rio de Janeiro (RMRJ), evidenciando a influência do ciclo diário e dos aspectos topográficos nas circulações locais. Na avaliação do padrão de vento foram utilizados dados horários provenientes de estações meteorológicas automáticas de superfície, organizados em gráficos de frequência de vento para o ciclo diário. Finalmente, os resultados evidenciam a modulação da circulação local de acordo com a atuação do sistema de brisa marítima-terrestre. Pode-se destacar a ocorrência de elevados percentuais de calmaria na estação Afonsos, caracterizando-a como uma região de estagnação, influenciada principalmente pelas feições topográficas locais. Este estudo disponibiliza um importante detalhamento da orientação e frequência do vento próximo à superfície, oferecendo subsídios adicionais às autoridades públicas para o aperfeiçoamento de suas políticas de gestão ambiental para a região.
\end{abstract}

Palavras-chave: vento em superfície; distribuição de frequência dos ventos; Região Metropolitana do Rio de Janeiro (RMRJ).

\begin{abstract}
This study deals with the characterization of surface wind regime in several sectors of Rio de Janeiro Metropolitan Region, and demonstrates the influence of daily wind cycle and the topographic aspects in the local wind circulations. For the evaluation of the wind pattern, it was used hourly data from different automatic surface meteorological stations. Afterward, these hourly data were organized in daily wind frequency. The results clearly showed that the modulation of local wind circulation follows the sealand breeze system. It was remarkable the high percentage of calm wind conditions observed in the Afonsos weather station, which characterizes this station as a stagnation region influenced essentially by its local topographic features. Finally, this study provides large database on the direction and frequency of surface wind in the Rio de Janeiro Metropolitan Region, which could be used by the public authorities to improve their environmental management policy for the region.
\end{abstract}

Keywords: surface wind; wind frequency distribution; Rio de Janeiro Metropolitan Region.

\section{INTRODUÇÃO}

A caracterização do regime de vento é de suma importância no planejamento das atividades industriais, com desdobramentos no processo de geração de energia e seus impactos na qualidade ambiental. Na literatura científica, os estudos abordam de maneira distinta a caracterização do regime de vento próximo à superfície, seja quanto ao método de obtenção dos dados (observacional ou via modelagem computacional da atmosfera) ou quanto à aplicação das informações.

Um estudo indicando a associação entre o regime de vento, o fenômeno da ilha de calor urbana e a poluição atmosférica na cidade do México foi desenvolvido por Jauregui (1988). O autor destacou que, principalmente no período noturno, o vento local, gerado termicamente, conduziu a altos níveis de concentração de poluentes nas proximidades das áreas urbanas. Carvalho (2006) destacou a influência do regime de vento sobre o mecanismo de dispersão de poluentes na Região Metropolitana do Rio de Janeiro (RMRJ), indicando as principais áreas de transporte de precursores do ozônio. Sahin et al. (2005) avaliaram o potencial de geração de energia eólica na Costa Leste da Turquia, a partir de dados de regime de vento provenientes de sete estações meteorológicas

口-

'Doutor em Engenharia Mecânica pela Universidade Federal do Rio de Janeiro (UFRJ). Professor associado III do Departamento de Meteorologia da UFRJ - Rio de Janeiro (RJ), Brasil. 2Doutor em Meteorologia pela Universidade de São Paulo (USP). Professor associado II do Departamento de Meteorologia da UFRJ - Rio de Janeiro (RJ), Brasil... ${ }^{3}$ Mestrando em Engenharia Mecânica pela COPPE/UFRJ. Graduado em Meteorologia pela UFRJ - Rio de Janeiro (RJ), Brasil.

${ }^{4}$ Meteorologista do Sistema Alerta Rio da Fundação Instituto de Geotécnica do Município do Rio de Janeiro. Graduado em Meteorologia pela UFRJ - Rio de Janeiro (RJ), Brasil Endereço para correspondência: Luiz Cláudio Gomes Pimentel - Avenida Athos da Silveira Ramos, 274 - 21941-916 - Rio de Janeiro (RJ), Brasil - E-mail: pimentel65@gmail.com Recebido: 08/02/12 - Aceito: 02/10/13 - Reg. ABES: 222 
referentes ao período de 1992-2000, destacando a viabilidade da geração de energia elétrica a partir dessa fonte de energia. Gokçek et al. (2007) desenvolveram uma investigação da caracterização do regime de vento e do potencial de energia eólica para Kirklareli, na Turquia, considerando dados de vento que indicaram um baixo potencial de geração de energia eólica na região.

Um estudo de caracterização do regime de vento em superfície para fins de geração de energia eólica encontra-se disponibilizado no Atlas Eólico do Estado do Rio de Janeiro (2002). O estudo foi desenvolvido a partir da modelagem atmosférica de mesoescala resultante do sistema MesoMAP (conjunto integrado de modelos de simulação atmosférica, bases de dados meteorológicos e geográficos, redes de computadores e sistema de armazenamento), utilizando dados de reanálises do National Centers for Environmental Prediction (NCEP) para um período de 15 anos.

A metodologia empregada na obtenção do campo de vento é fortemente dependente dos resultados numéricos da modelagem atmosférica e respectivas condições de contorno. Notou-se, na análise das rosas de vento disponibilizadas no Atlas Eólico, que ocorreram algumas distorções no regime de vento modelado, principalmente para a região da Baía de Sepetiba, onde os dados observados indicam predominância de SW e NE e os resultados do MesoMAP apresentam direção predominante de NE e SE.

Truccolo (2011) avaliou comparativamente o regime de vento em Navegantes e Praia Grande, no litoral Centro-Norte de Santa Catarina, a partir de registros horários de direção e intensidade do vento e de uma análise estatística no domínio do tempo-frequência durante os meses de julho a dezembro de 1996. No estudo foi observada uma diferenciação da circulação em superfície, apesar da proximidade entre as duas localizações. Identificou-se um comportamento do vento norte-sul na estação de Praia Grande, similar ao regime do vento na Região Sul-Sudeste brasileira, com pouca influência dos efeitos locais como o sistema de brisas. Para a região de Navegantes, com predominância de vento de direção sul, o regime de vento é conduzido pela combinação do sistema de brisa terra-mar e de vale-montanha, resultante do Vale do Itajaí.

Alves e Silva (2011) destacam a importância do conhecimento do regime de vento para as ciências agroambientais, como em estudos voltados para o controle da propagação de doenças, aplicação de defensivos agrícolas e entendimento do processo de polinização. Os autores remarcam que no Brasil os estudos sobre a caracterização do regime de vento ainda são escassos e não retratam a distribuição espacial e temporal dos ventos nas regiões brasileiras, principalmente nas áreas de interesse socioambiental.

O sítio em que se assenta a RMRJ, destacado pela alta ocupação populacional e industrial, constitui um importante fator na caracterização do regime de vento, identificação da direção predominante e ocorrência de calmaria. A localização dos maciços da Tijuca, Pedra Branca e Gericinó, que delimitam áreas de baixada cercadas de pequenas serras e morros isolados, a presença do mar e das baías da Guanabara e Sepetiba e a ocupação irregular do solo, constituem os principais domínios geográficos da RMRJ. Esses aspectos, em conjunto com a própria estrutura urbana, localização das indústrias e configuração viária, desempenham importante papel no regime de ventos e transporte de poluentes na região.

Segundo o relatório do INEA (2009), o estado do Rio de Janeiro, em termos de poluição do ar, apresenta duas áreas críticas que necessitam de subsídios para ações de controle ambiental: a Região Metropolitana e a Região do Médio Paraíba. Esses problemas tendem a se agravar com a entrada em operação de novos empreendimentos, como a Companhia Siderúrgica do Atlântico, instalada próximo à Baía de Sepetiba, o pólo de refino do Complexo Petroquímico do Rio de Janeiro (COMPERJ), em Itaboraí, e principalmente o futuro incremento da atividade de exploração de petróleo na camada do Pré-sal, na região da Bacia de Campos.

Deve-se destacar que a cidade do Rio de Janeiro se prepara para receber os dois maiores eventos esportivos do mundo, a Copa do Mundo de 2014 e as Olimpíadas de 2016, para os quais se esperam grandes investimentos em diversas áreas e uma intensa dinamização do turismo, reforçando a necessidade da investigação e conhecimento dos aspectos climatológicos da região, contribuindo para a otimização e sucesso desses eventos.

A análise dos estudos científicos disponíveis na literatura evidencia que, apesar da necessidade urgente da identificação do regime de vento e sua associação com a precipitação, transporte de poluentes, processo de formação de nevoeiro, da ilha de calor urbana e brisa terra/mar, no caso específico do estado do Rio de Janeiro há uma carência de estudos que caracterizem a dinâmica das circulações locais na região. Pode-se destacar que o conhecimento do regime de vento nessa região possibilita a identificação antecipada das áreas que poderão sofrer o impacto das emissões atmosféricas de novos empreendimentos e, assim, auxiliar estratégias de monitoramento da qualidade do ar e de mitigação do problema.

Dessa forma, o objetivo deste trabalho foi caracterizar o regime de vento próximo à superfície nos setores Oeste, CentroSul e Leste da RMRJ, avaliando o efeito do ciclo diário e a influência dos aspectos topográficos e de corpos d'água nas circulações locais. Adicionalmente, a caracterização do regime de vento na região pode contribuir na avaliação de modelos computacionais da atmosfera e da qualidade do ar, na representação físico-matemática dos mecanismos de dispersão de poluentes e no auxílio à gestão ambiental na RMRJ. 


\section{METODOLOGIA}

A área de estudo compreende as bacias aéreas I, II e III, segundo a classificação estabelecida em FEEMA (2004), inserida na RMRJ.

Para a caracterização da distribuição horizontal do vento na região de estudo foram utilizados dados horários de direção e intensidade dos ventos observados em oito estações meteorológicas automáticas de superfície, em diferentes localidades da RMRJ. A localização geográfica das estações de superfície, juntamente com a elevação do terreno na região estudada, são apresentadas na Figura 1. Destacam-se os maciços de Gericinó e da Pedra Branca, separando as regiões Oeste e Centro-Sul e o Maciço da Tijuca, entre as regiões Centro-Sul e Leste da região de estudo. Na Região Oeste estão localizadas as estações de Santa Cruz (SBSC) e Seropédica (estação Ecologia Agrícola); na Região Centro-Sul encontram-se as estações Jacarepaguá (SBJR), Jacarepaguá/INEA (JPA) e Afonsos (SBAF), e a Região Leste é aqui representada pelas estações Santos
Dumont (SBRJ), Centro e Galeão (SBGL). Esta divisão da região em sub-regiões tem como objetivo procurar estabelecer padrões característicos do regime de ventos em superfície.

Os dados meteorológicos referentes aos aeródromos Galeão, Santos Dumont, Jacarepaguá (SBJR), Santa Cruz e Afonsos são provenientes do código METAR, disponibilizados na Rede de Meteorologia do Comando da Aeronáutica (www.redemet.aer.mil. br). Os dados das estações Centro e Jacarepaguá/INEA (JPA) foram cedidos pelo Instituto Estadual do Ambiente (INEA). As informações da estação automática de superfície no município de Seropédica foram cedidas pelo Instituto Nacional de Meteorologia (INMET - www.inmet.gov.br).

Os períodos das observações não são totalmente coincidentes entre as estações, porém estes possuem intervalos temporais comuns entre os anos de 2000 e 2007. O tratamento dos dados foi feito a partir da composição em rosas dos ventos para cada uma

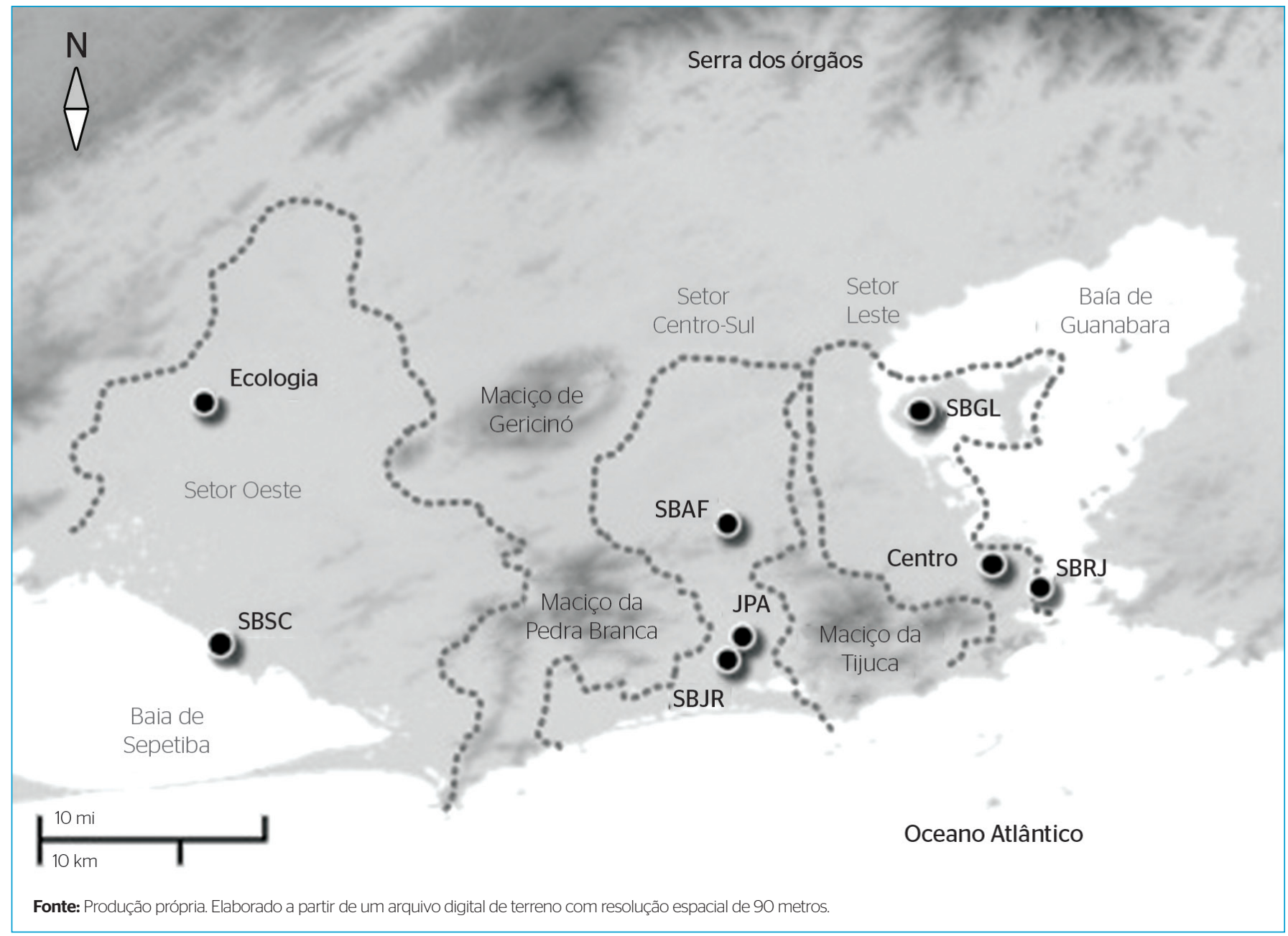

Figura 1 - Localização geográfica das estações de superfície na Região Metropolitana do Rio de Janeiro (pontos pretos). Destacam-se os maciços de Gericinó (ao norte) e da Pedra Branca (ao sul) separando os setores Oeste e Centro-Sul, e o Maciço da Tijuca entre os setores Centro-Sul e Leste da região de estudo. 
das oito estações de superfície, indicando simultaneamente a frequência de ocorrências e respectivas intensidades. Esse procedimento de apresentação das informações combinadas, considerando a direção e intensidade do vento, pode ser encontrado em diversos artigos disponíveis na literatura (MUNN, 1969; KOSE et al., 2004; UCAR \& BALO, 2009). O Programa WRPLOT utilizado nas rosas dos ventos está disponível no sítio www.weblakes.com/products/ wrplot. O padrão médio para cada localidade foi construído considerando todos os horários diários ( 0 h até $23 \mathrm{~h}$ ). A representação nos diferentes períodos do dia foi dividida em: madrugada $(0 \mathrm{~h}$ até $5 \mathrm{~h})$, manhã ( $6 \mathrm{~h}$ até $11 \mathrm{~h})$, tarde ( $12 \mathrm{~h}$ até $17 \mathrm{~h})$ e noite ( $18 \mathrm{~h}$ até 23 h). A Tabela 1 sintetiza essas informações de vento, ressaltando que nenhuma técnica de preenchimento de dados foi utilizada.

\section{RESULTADOS E DISCUSSÃO}

\section{Região Oeste}

A composição total dos ventos para a estação de Santa Cruz (SBSC) (Figura 2a), localizada próximo à Baía de Sepetiba, revela um padrão bem definido nas direções sudoeste e nordeste, com ventos máximos de aproximadamente 18 nós. Com relação ao ciclo diário, os períodos da tarde e da noite contribuem mais efetivamente para a direção sudoeste (Figuras $2 \mathrm{~b}$ e $2 \mathrm{c}$ ), enquanto que a madrugada e a manhã contribuem para a direção nordeste (Figuras 2 d e 2e). Em Seropédica, o padrão total é caracterizado pelas direções sudoeste e norte, com ventos máximos de 15 nós (Figura 3a). Os períodos da tarde e noite, representados nas Figuras $3 \mathrm{~b}$ e $3 \mathrm{c}$, justificam o padrão sudoeste observado no local, enquanto que os períodos da madrugada e manhã possuem predominância de ventos do quadrante norte, como observado nas Figuras $3 \mathrm{~d}$ e $3 \mathrm{e}$.
A análise dos ventos na Região Oeste indica marcante modulação pelo mecanismo de brisa marítima-terrestre, apresentando direção da circulação perpendicular à orientação do litoral, principalmente na estação de Santa Cruz. Na estação de Seropédica, posicionada no interior da Baixada de Santa Cruz, a brisa terrestre (madrugada/manhã) não é exatamente perpendicular ao contorno do litoral (Baía de Sepetiba), indicando a influência de outras circulações locais, como a brisa de vale-montanha. Estes resultados observacionais diferem significativamente de resultados numéricos obtidos a partir da modelagem atmosférica regional. Citam-se, como exemplo: Atlas Eólico do Estado do Rio de Janeiro (2002); Silva e Santos (2006); Corrêa et al. (2007).

Os resultados de modelagem evidenciam uma especial dificuldade na representação dos ventos da brisa marítima, configurando componentes S e SE, ao invés da direção SW observada nas estações Santa Cruz e Seropédica. Essa discrepância entre a modelagem numérica e as observações pode estar relacionada com uma inadequada representação físico-matemática das forçantes que induzem a circulação local. O detalhamento da orientação e frequência do vento próximo à superfície pode fornecer informações importantes para a adequação dos modelos atmosféricos à representação dos mecanismos dinâmicos que atuam na região.

\section{Região Centro-Sul}

A Região Centro-Sul é aqui representada pelas estações dos aeródromos de Jacarepaguá e Afonsos e pela estação Jacarepaguá/INEA. A região da estação do aeródromo de Jacarepaguá é caracterizada, principalmente, por um padrão total de vento nas direções norte e sul, com valores máximos de 13 nós (Figura 4a). A ausência de dados no período noturno inviabilizou uma análise dos períodos da noite e da madrugada, mas as rosas dos ventos dos períodos da

Tabela 1 - Informações sobre as estações meteorológicas de superfície, respectivas fontes e os períodos dos dados horários utilizados. A letra A indica ausência de dados, I dados incompletos e C período completo.

\begin{tabular}{|c|c|c|c|c|c|c|c|c|c|c|}
\hline Estação & Fonte & Número de observações & 2000 & 2001 & 2002 & 2003 & 2004 & 2005 & 2006 & 2007 \\
\hline SBGL & METAR & 44.760 & A & A & C & C & । & C & I & C \\
\hline SBRJ & METAR & 46.564 & A & A & I & C & । & C & I & C \\
\hline SBJR & METAR & 27.048 & A & A & I & C & । & C & । & C \\
\hline SBAF & METAR & 40.064 & A & A & । & C & । & C & । & C \\
\hline SBSC & METAR & 43.869 & A & A & A & C & C & C & C & C \\
\hline Centro & INEA & 52.120 & I & । & । & C & C & C & । & । \\
\hline Jacarepaguá & INEA & 52.191 & । & । & । & C & I & C & I & । \\
\hline Eco. Agrícola & INMET & 59.946 & I & I & C & C & I & C & C & C \\
\hline
\end{tabular}




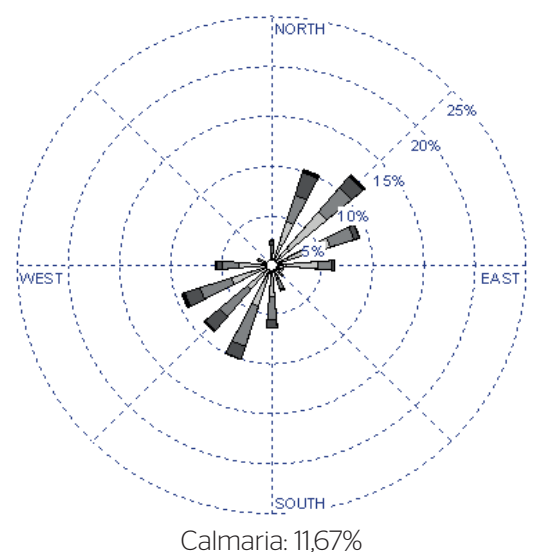

(a)

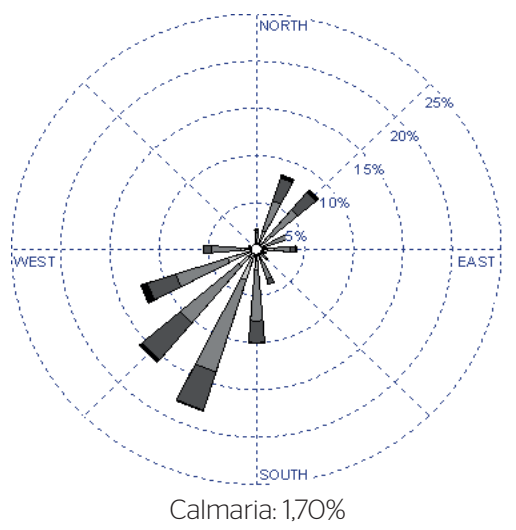

(b)

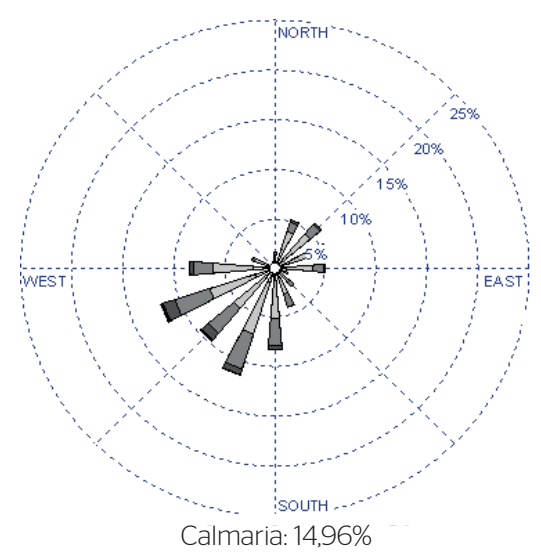

(c)

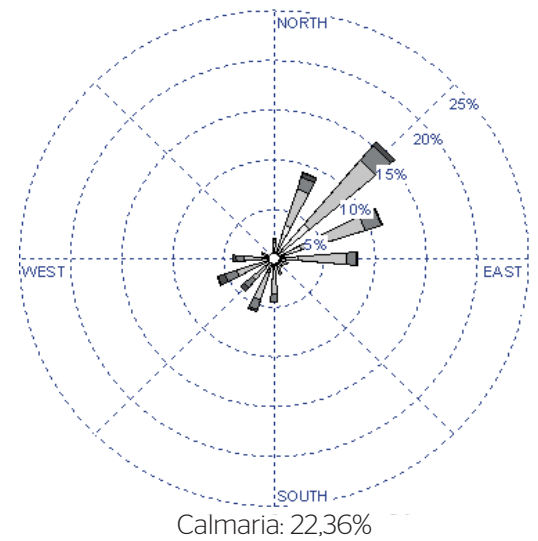

(d)

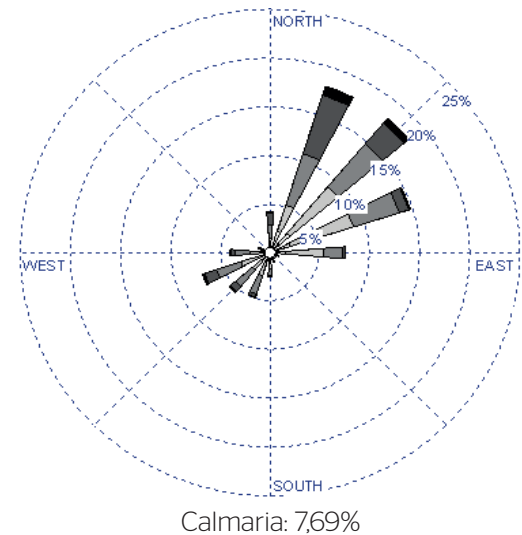

(e)

Vel. (nó) $\geq 17$ $17-11$
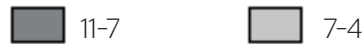
4-1

Fonte: Produzido a partir do software WRPLOT View.

Figura 2 - Distribuição de frequência dos ventos para a estação Santa Cruz, referentes a: (a) composição total e períodos (b) tarde, (c) noite, (d) madrugada, (e) manhã.

tarde e da manhã são apresentadas nas Figuras 4 b e 4c. Identificou-se que a direção sul ocorre predominantemente à tarde, e a direção norte ocorre com maior frequência durante a manhã.

Na estação Jacarepaguá/INEA o padrão total dos ventos é semelhante ao padrão do aeródromo, exceto por um deslocamento no sentido horário na visualização da rosa dos ventos (Figura 5a), caracterizando direções dos ventos ligeiramente deslocadas para sul/sudoeste e nordeste. Os períodos da tarde e da noite (Figuras $5 \mathrm{~b}$ e 5c) possuem predominância de ventos de sul/sudoeste, enquanto os períodos da madrugada e da manhã (Figuras $5 \mathrm{~d}$ e $5 \mathrm{e}$ ) contribuem principalmente com os ventos de baixa intensidade do quadrante norte.

Na estação localizada no aeródromo de Afonsos destacam-se ventos de sul de até 15 nós no seu padrão total e uma contribuição menos frequente de ventos de sudoeste e leste (Figura 6a). Com relação ao ciclo diário, o período da tarde evidencia vento de direção sul bem definido (Figura 6b). À noite, o vento sul apresenta-se menos frequente e menos intenso, enquanto que os ventos de leste atingem sua maior representatividade no ciclo diário (Figura 6c).

O padrão dos ventos na parte centro-sul da região de estudo é consistente com a atuação das brisas marítimas e terrestres nos respectivos períodos, tarde/noite e madrugada/manhã. A influência topográfica na circulação também pode ser evidenciada na região. Apesar da proximidade entre as duas estações em Jacarepaguá, existem diferenças marcantes no padrão de vento predominante entre as mesmas, uma vez que uma delas (no aeródromo) está localizada próximo a corpos d'água (lagoas e mar), e a outra se encontra inserida em área urbana (estação INEA). $\mathrm{Na}$ estação Afonsos, à tarde, os ventos de sul revelam a marcante atuação da brisa marítima no local, porém no período madrugada/manhã os ventos são fracos e não apresentam uma direção preferencial. 


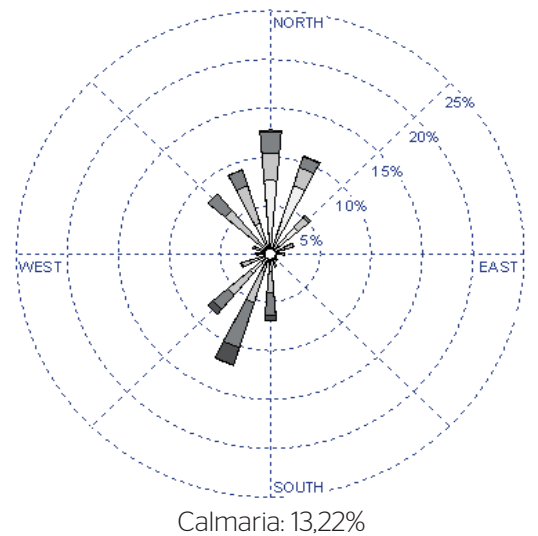

(a)

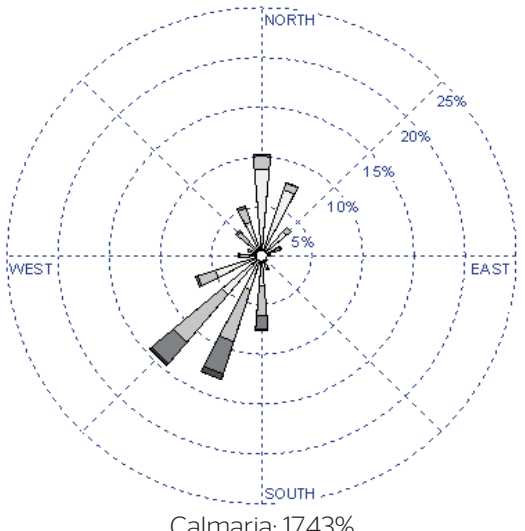

(c)

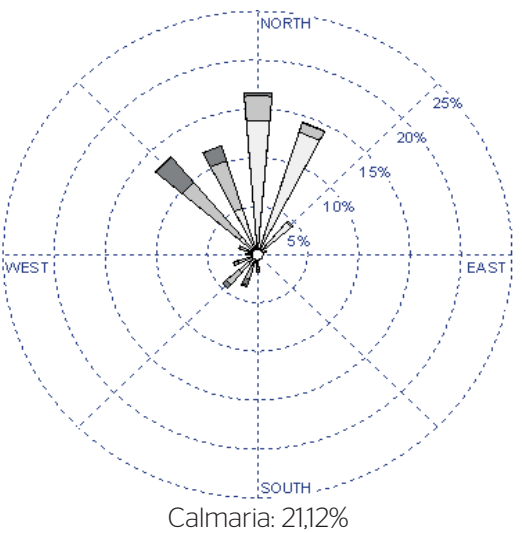

(d)

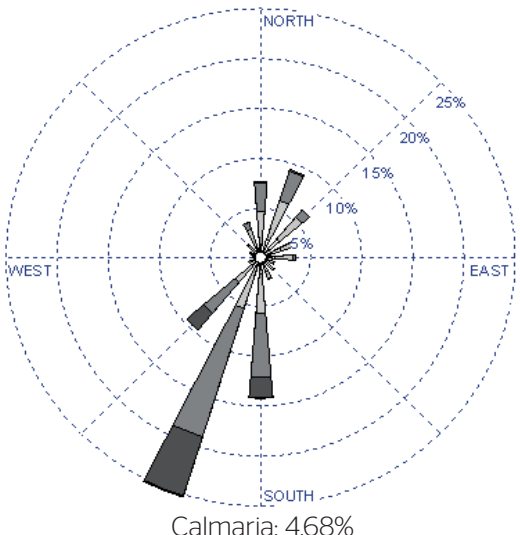

(b)

Vel. (nó)

$\geq 17$

$\square$ 17-11

$\square$ 11-7

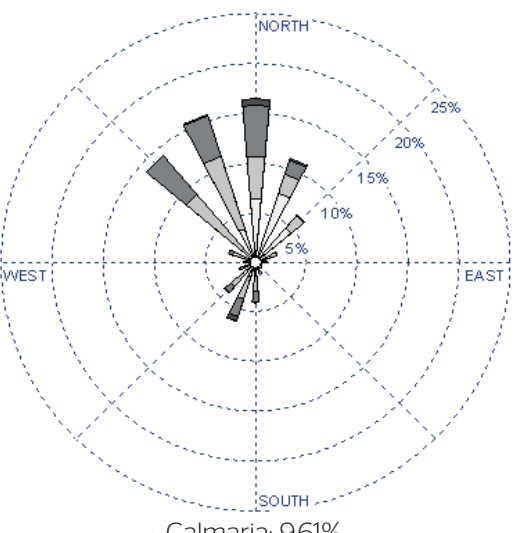

Calmaria: 9,61\%

(e)

Fonte: Produzido a partir do software WRPLOT View.

Figura 3 - Distribuição de frequência dos ventos para a estação Ecologia Agrícola, Seropédica, referentes a: (a) composição total e períodos (b) tarde, (c) noite, (d) madrugada, (e) manhã.

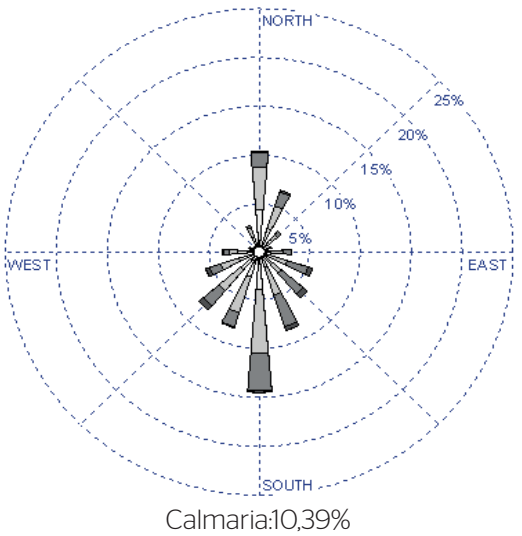

(a)

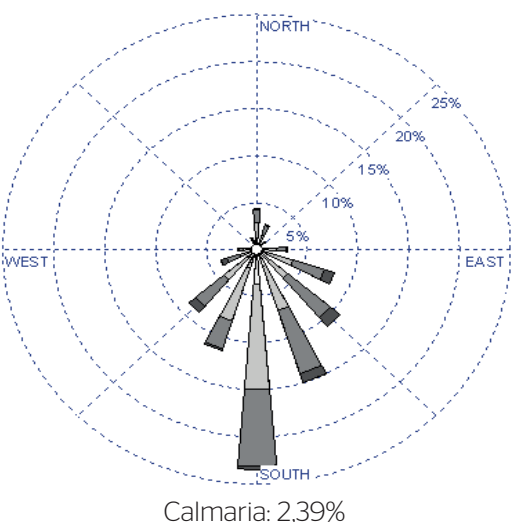

(b)

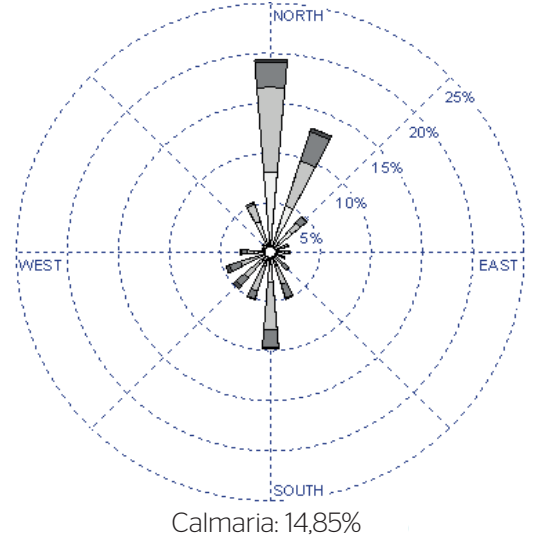

(c)

Vel. (nó) $\geq 17$ $17-11$ $11-7$ 4-1

Fonte: Produzido a partir do software WRPLOT View.

Figura 4 - Distribuição de frequência dos ventos para a estação Jacarepaguá, referentes a: (a) composição total e períodos (b) tarde, (c) manhã. 


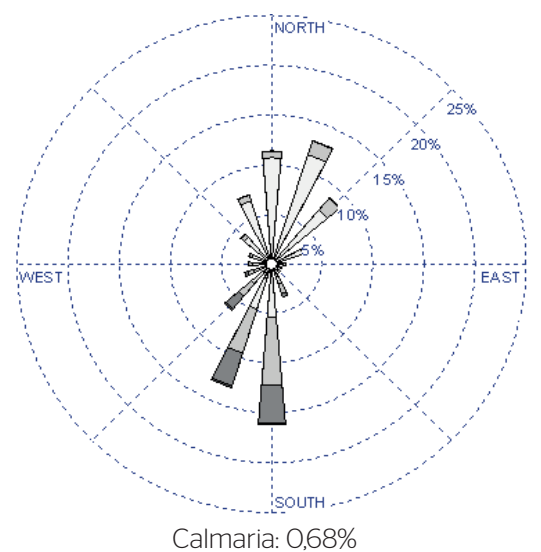

(a)

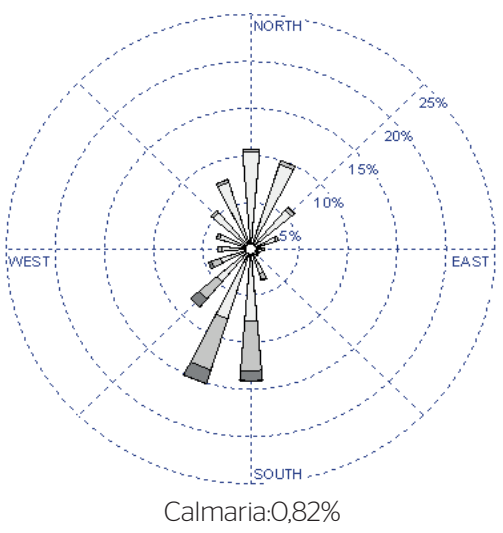

(c)

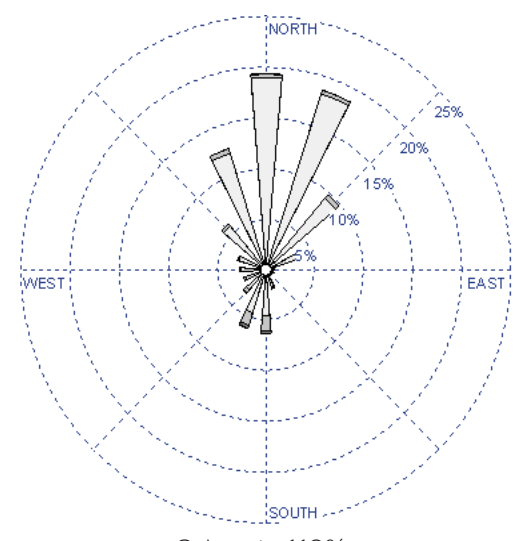

Calmaria: 1,10\%

(d)

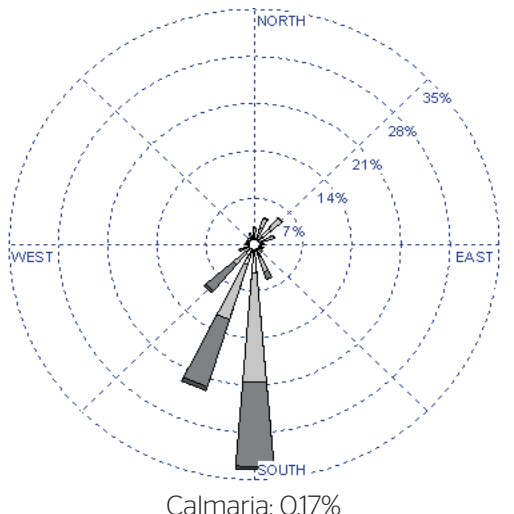

(b)

Vel. (nó) $\geq 17$

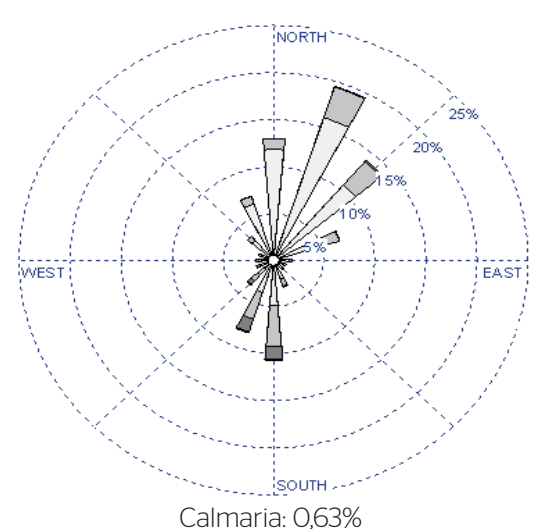

(e)

Fonte: Produzido a partir do software WRPLOT View.

Figura 5 - Distribuição de frequência dos ventos para a estação Jacarepaguá/INEA, referentes a: (a) composição total e períodos (b) tarde, (c) noite, (d) madrugada, (e) manhã.

\section{Região Leste}

A Região Leste é aqui representada pelo padrão dos ventos nas estações Santos Dumont, Centro e Galeão, localizadas na borda oeste da Baía de Guanabara (Figura 1). A estação do aeroporto Santos Dumont, próximo à entrada da baía, apresenta em sua composição total um padrão norte-sul evidente (Figura 7a). Com relação ao ciclo diário, os períodos da tarde e da noite contribuem mais efetivamente para os ventos do quadrante sul, atingindo $35 \%$ das observações no período da tarde e com ventos de até 15 nós, destacados nas Figuras $7 \mathrm{~b}$ e $7 \mathrm{c}$. Os períodos da madrugada e da manhã estão mais associados aos ventos do quadrante norte (Figuras $7 \mathrm{~d}$ e $7 \mathrm{e}$ ).

A estação Centro, localizada em uma área extremamente urbanizada, possui um padrão total de vento caracterizado pelas direções sudeste e noroeste (Figura 8a). A direção sudeste, observada na composição total, é resultado da contribuição dos períodos da tarde e da noite (Figuras $8 \mathrm{~b}$ e $8 \mathrm{c}$ ), principalmente. Por outro lado, a direção noroeste recebe a maior contribuição dos períodos da madrugada e da manhã (Figuras $8 \mathrm{~d}$ e $8 \mathrm{e}$ ). Destacam-se ainda ventos intensos de leste de aproximadamente 18 nós, com frequência de observação relativamente baixa $(\sim 5 \%)$ e presentes em todos os períodos do dia. A influência da urbanização, por meio da formação de corredores por entre os edifícios, pode estar contribuindo para esta característica de ventos de leste no local.

Na estação do aeroporto do Galeão, localizado na Ilha do Governador, o padrão total de vento é distribuído em diversas direções, com predominância de sudeste e leste (Figura 9a). Na parte da tarde e da noite as direções sudeste e leste são as mais observadas, sendo que o período da tarde apresenta um padrão predominante de sudeste bem evidente e com ventos mais intensos de até 15 nós (Figuras 9b e 9c). Os períodos da madrugada e da manhã apresentam ventos nas mais variadas direções, destacando-se as direções leste e norte como as mais frequentes, com 


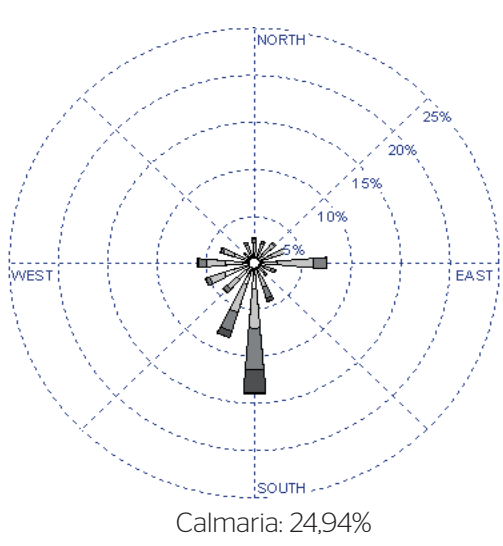

(a)

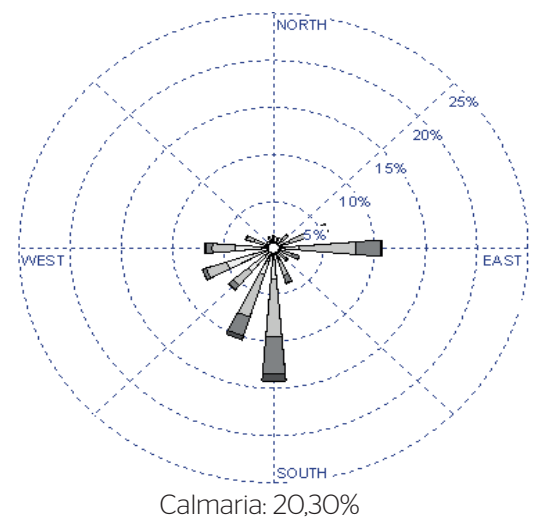

(c)

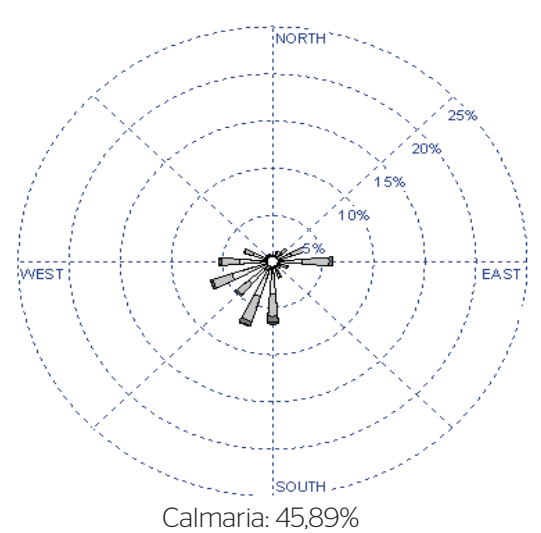

(d)

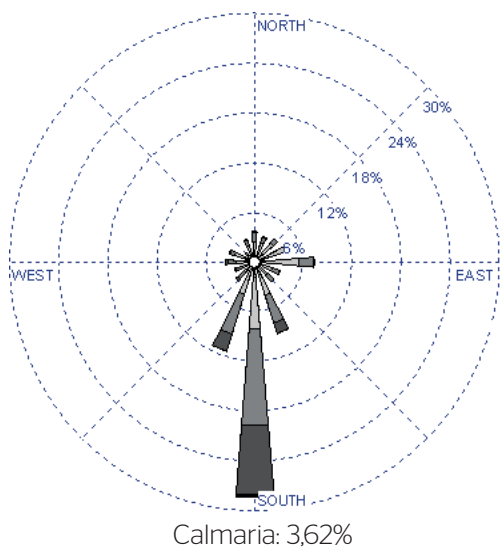

(b)

Vel. (nó) $\geq 17$

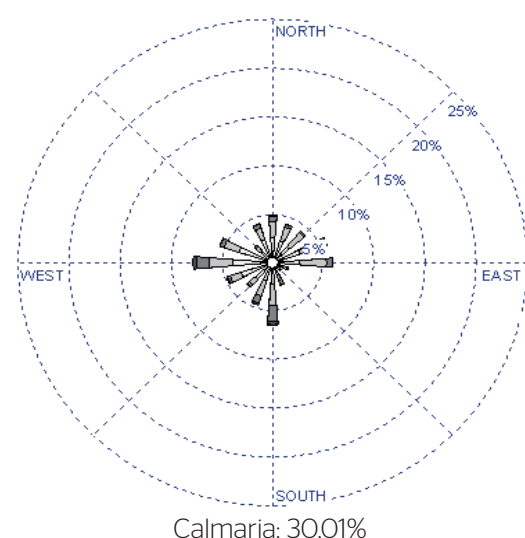

(e)

Fonte: Produzido a partir do software WRPLOT View.

Figura 6 - Distribuição de frequência dos ventos para a estação Afonsos, referentes a: (a) composição total e períodos (b) tarde, (c) noite, (d) madrugada, (e) manhã.

aproximadamente $12 \%$ do total das observações nos respectivos períodos (Figuras 9d e 9e).

$\mathrm{Na}$ análise das rosas dos ventos observam-se discrepâncias com relação ao padrão de vento apresentado no Atlas Eólico do Estado do Rio de Janeiro (2002). Neste último, destaca-se a predominância de ventos na direção norte-sudeste em toda a Região Leste, não sendo evidenciada a variabilidade espacial do regime do vento, como detectado a partir dos dados observacionais apresentados nas Figuras 7 a 9.

\section{ANÁLISE DO REGIME DE CALMARIA E INFLUÊNCIA DA SAZONALIDADE}

Na Tabela 2 apresenta-se o percentual de calmaria em cada uma das oito estações consideradas. A situação de calmaria é considerada quando a magnitude do vento se apresenta inferior a 1 nó $\left(0,515 \mathrm{~m} \cdot \mathrm{s}^{-1}\right)$. A estação Afonsos destaca-se pelo maior percentual de calmaria em relação ao total de registros em sua série temporal de vento, atingindo o total de $25 \%$. Este percentual é bastante elevado e corresponde a aproximadamente o dobro do que foi registrado em Seropédica, que é a estação com o segundo maior índice (13\%). Nota-se que os maiores percentuais de calmaria ocorrem sempre de madrugada, tendo a estação Afonsos o maior percentual neste período (46\%). Ou seja, praticamente metade dos registros de vento durante a madrugada naquela localidade encontra-se nesse regime. Como destacado anteriormente, o posicionamento da estação Afonsos, entre os maciços de Gericinó, Pedra Branca e da Tijuca, confere a esta localidade um padrão de estagnação dos ventos. De maneira geral, o percentual de calmaria nas estações aumenta gradativamente da noite para a madrugada, e depois reduz no período da manhã. Verifica-se que apesar dessa redução no período da manhã, as 


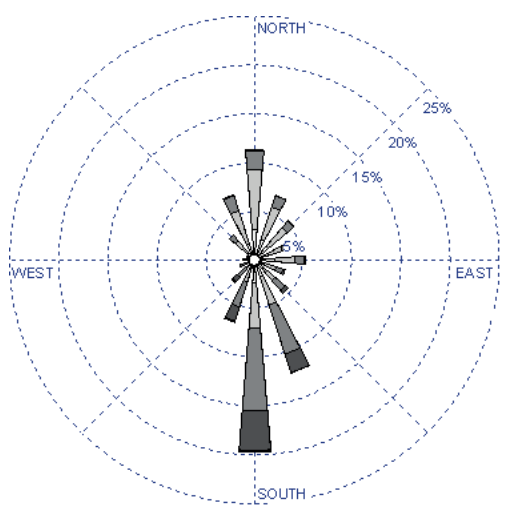

Calmaria: $3,50 \%$

(a)

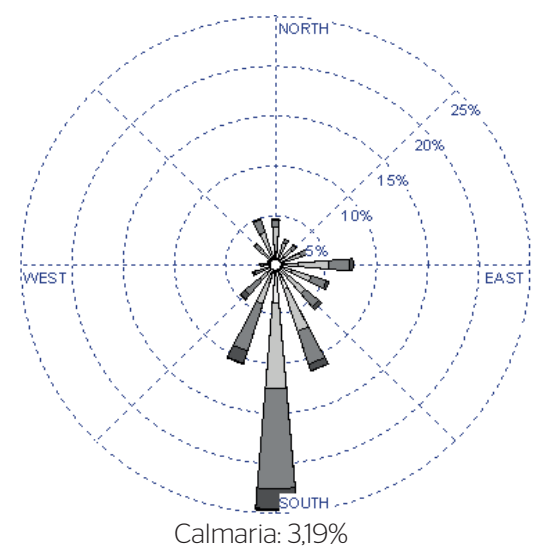

(c)

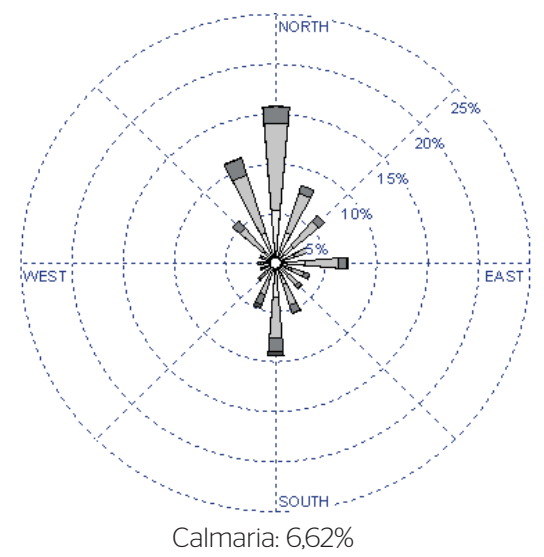

(d)

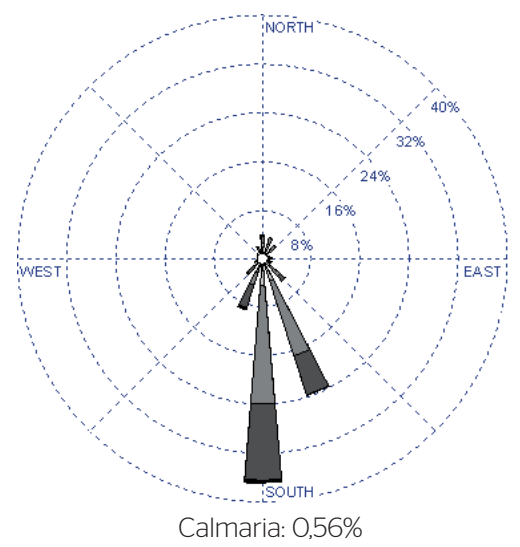

(b)

Vel. (nó) $\geq 17$ $17-11$

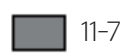

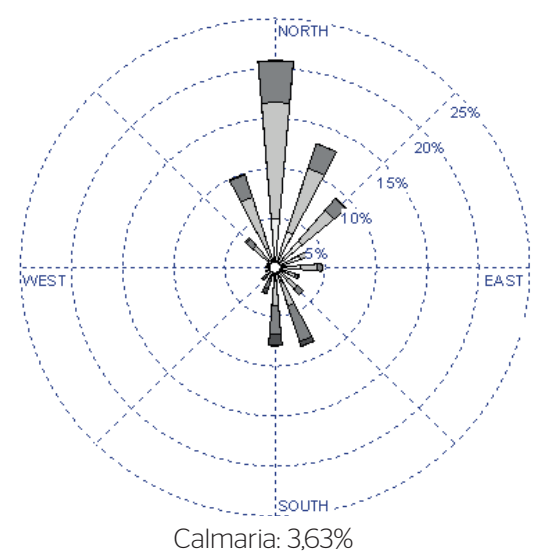

(e)

Fonte: Produzido a partir do software WRPLOT View.

Figura 7 - Distribuição de frequência dos ventos para a estação Santos Dumont, referentes a: (a) composição total e períodos (b) tarde, (c) noite, (d) madrugada, (e) manhã.

estações Afonsos e Galeão continuam registrando percentuais muito superiores aos observados durante a noite. Fatores como o posicionamento da primeira entre três grandes maciços, e da segunda no interior da Baía de Guanabara, podem contribuir para essa relativa dificuldade na diminuição dos percentuais de calmaria nessas localidades.

Complementando a caracterização do regime de ventos na região, uma inspeção da sazonalidade foi desenvolvida, e observou-se pouca variação no padrão dos ventos em superfície. Isto reflete a característica essencial da circulação térmica, a qual é uma resposta diretamente ligada à distribuição espacial do gradiente térmico e não ao valor absoluto da temperatura. Entretanto, algumas diferenças na intensidade e no percentual de frequência da direção dos ventos foram observadas, indicando a importância do ângulo de incidência da radiação solar em relação à orientação e cobertura da superfície.
Tabela 2 - Percentual de calmaria nas estações de superfície em relação ao total dos dados e considerando separadamente os períodos da tarde, noite, madrugada e manhã.

\begin{tabular}{l|c|c|c|c|c} 
Estação & \% Total & \% Tarde & $\%$ Noite & $\begin{array}{c}\text { \% Madru- } \\
\text { gada }\end{array}$ & \% Manhã \\
\hline SBSC & 12 & 2 & 15 & 22 & 8 \\
\hline $\begin{array}{l}\text { Ecologia } \\
\text { Agrícola }\end{array}$ & 13 & 5 & 17 & 21 & 10 \\
\hline SBJR & - & 2 & - & - & 15 \\
\hline Jacarepaguá & 1 & $0 *$ & 1 & 1 & 1 \\
\hline SBAF & 25 & 4 & 20 & 46 & 30 \\
\hline SBRJ & 4 & 1 & 3 & 7 & 4 \\
\hline Centro & 3 & 1 & 4 & 7 & 2 \\
\hline SBGL & 8 & $*$ & 4 & 15 & 11 \\
\hline
\end{tabular}

(*) Percentual de ocorrência abaixo de $1 \%$. 


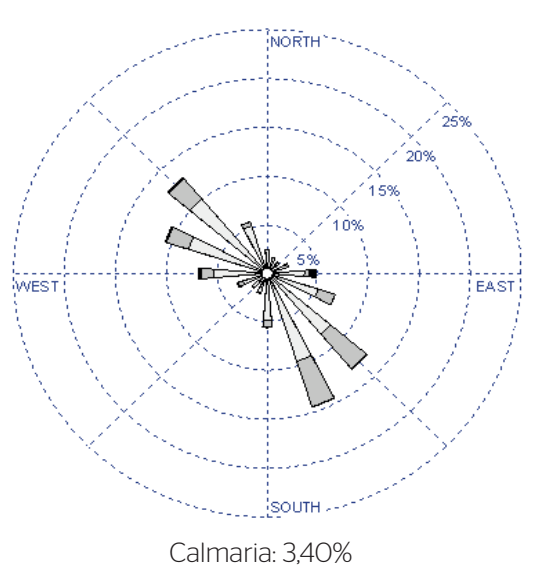

(a)

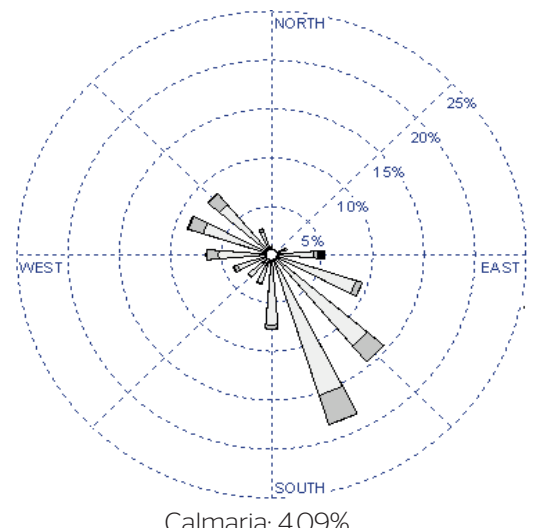

(c)

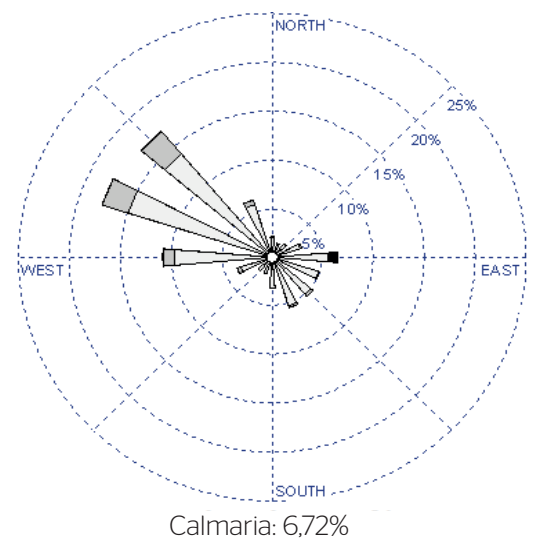

(d)

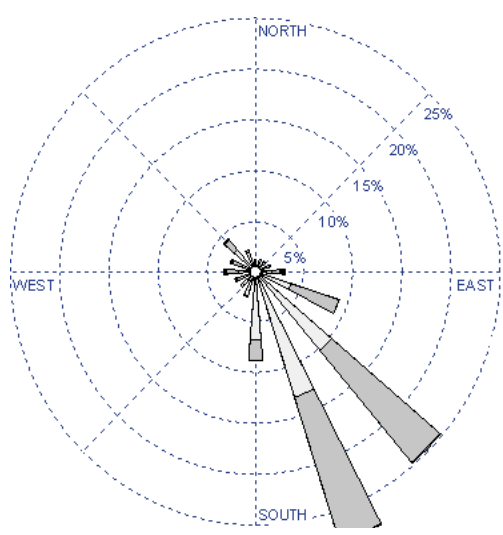

Calmaria: 0,65\%

(b)

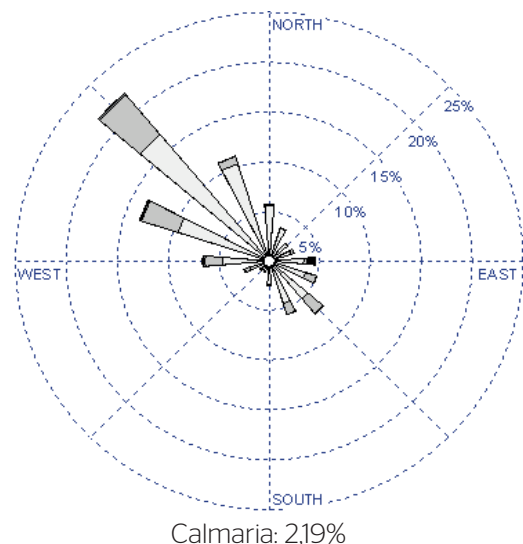

(e)

Vel. (nó) $\geq 17$

Fonte: Produzido a partir do software WRPLOT View.

Figura 8 - Distribuição de frequência dos ventos para a estação Centro, referentes a: (a) composição total e períodos (b) tarde, (c) noite, (d) madrugada, (e) manhã.

\section{CONCLUSÕES}

Este trabalho teve como importante contribuição a disponibilização de informações do regime de vento em superfície, obtidas a partir de dados observacionais, que permitem avaliar modelos computacionais da atmosfera e serem usados como referência para o aperfeiçoamento do Atlas Eólico do Estado do Rio de Janeiro. Isso ressalta a importância da adequada configuração dos modelos de mesoescala para a modelagem dos processos físicos na região, exigindo um refinamento das condições de contorno, com alta resolução da base de dados topográficos e de uso do solo, detalhamento da linha de costa e boa representação dos processos de camada limite e de transferência radiativa.

$\mathrm{Na}$ análise da distribuição de frequência dos ventos fica evidenciada a modulação da circulação local de acordo com a atuação do sistema de brisa marítima-terrestre. Os padrões de vento aqui descritos permitem destacá-los em três regiões distintas: Oeste, Centro-Sul e Leste.

Nas Regiões Oeste e Centro-Sul, os ventos formados pelas brisas marítimas e terrestres são aproximadamente perpendiculares ao contorno da costa. As estações localizadas mais no interior do continente, nessas duas regiões, são mais influenciadas pela elevação irregular do terreno. Outro aspecto que merece destaque são os ventos na Região Centro-Sul que, por estarem confinados entre os maciços da Pedra Branca e da Tijuca, formam um corredor de ventos com predominância nas direçõesnorte-sul.

Na Região Leste, os ventos aproximadamente perpendiculares ao contorno da costa ocorrem somente nas estações Centro e Galeão. A presença da Baía de Guanabara parece produzir um efeito de canalização, 


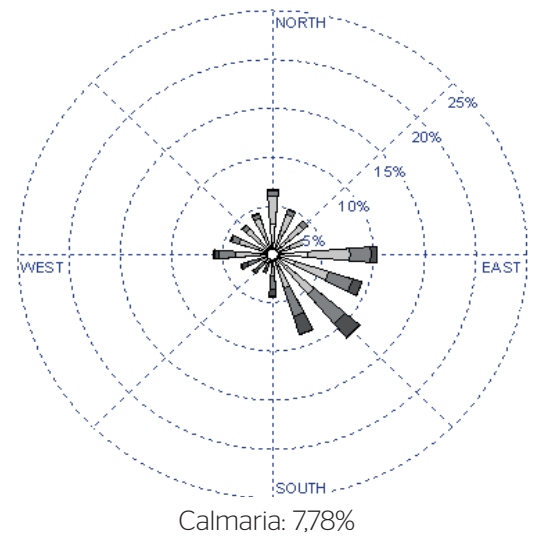

(a)

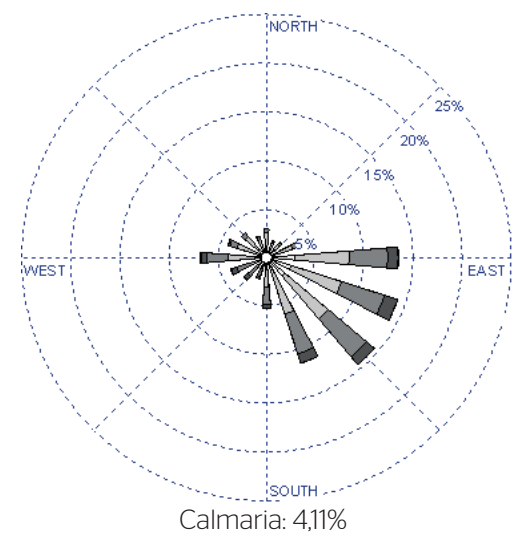

(c)

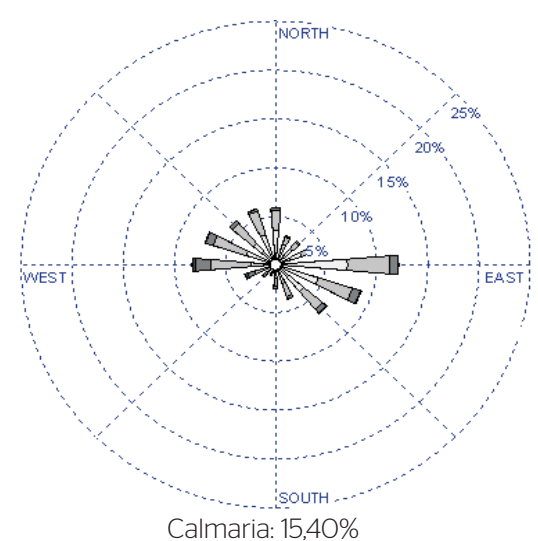

(d)

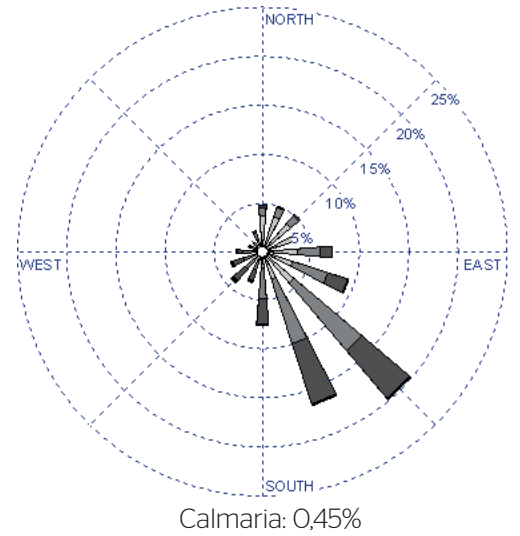

(b)

\section{Vel. (nó)} $\geq 17$

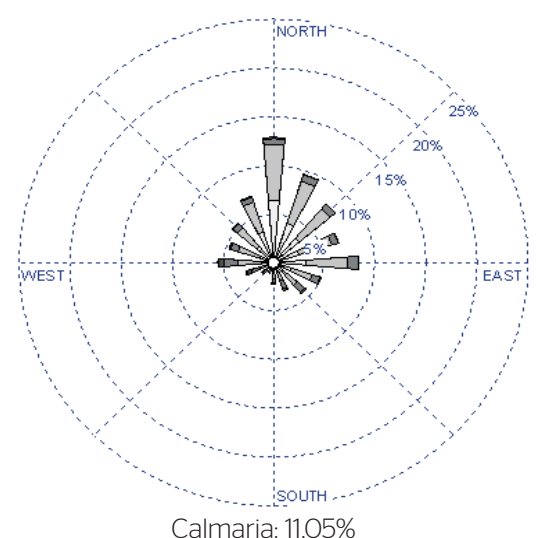

(e)

Fonte: Produzido a partir do software WRPLOT View.

Figura 9 - Distribuição de frequência dos ventos para a estação Galeão, referentes a: (a) composição total e períodos (b) tarde, (c) noite, (d) madrugada, (e) manhã.

bastante evidente no padrão norte-sul na estação Santos Dumont, localizada na entrada da baía.

Com relação ao regime de calmaria, pode-se destacar que na estação Afonsos foram observados percentuais elevados, sendo mais evidentes na madrugada. Certamente, a barreira topográfica formada pelos maciços contribui significativamente para o elevado percentual de calmaria e na diversidade de direções dos ventos observados.

A análise da influência sazonal indicou pouca variação no padrão dos ventos em superfície, evidenciando a predominância das forçantes locais nos diversos setores da RMRJ.

\section{REFERÊNCIAS}

ALVES, E.D.L. \& SILVA, S.T. (2011) Direção e velocidade do vento em uma floresta de transição Amazônia-Cerrado no norte de Mato Grosso, Brasil. B.goiano.geogr, v. 31, n.1, p. 63-74.

ATLAS EÓLICO DO ESTADO DO RIO DE JANEIRO (2002) Secretaria de Estado de Energia, da Energia, da Indústria Naval e do Petróleo. Elaborado por Camargo Schubert Engenharia Eólica.
CARVALHO, V.S.B. (2006) Meteorologia da qualidade do ar no que tange as concentrações de ozônio e dos óxidos de nitrogênio na Região Metropolitana do Rio de Janeiro. Dissertação (Mestrado), Programa de Engenharia Mecânica - COPPE, UFRJ, 134 p.

CORRÊA, E.B.; SOARES, M.S.; PIMENTEL, L.C.G. (2007) Modelagem do escoamento atmosférico na RMRJ com os modelos MM5 e CALMET - Parte II. Ciência e Natura, v. Especial, p. 281-284. 
FEEMA - FUNDAÇÃO ESTADUAL DE ENGENHARIA DO MEIO AMBIENTE. (2004) Inventário de fontes emissoras de poluentes atmosféricos da Região Metropolitana do Rio de Janeiro. Departamento de Planejamento Ambiental, Divisão de Qualidade do Ar, Rio de Janeiro - RJ, Brasil.

GOKÇEK, M; BAYULKEN, A.; BEKIDEMIR, S. (2007) Investigation of wind characteristics and wind energy potential in Kirklareli, Turkey, Renewable Energy, v. 32, p.1739-1752.

INEA - INSTITUTO ESTADUAL DO AMBIENTE. (2009) Relatório anual da qualidade do ar do estado do Rio de Janeiro. Rio de Janeiro - RJ, Brasil.

JAUREGUI, E. (1988) Local wind and air pollution interaction in the Mexico Basin. Atmósfera, v. 1, p. 131-140.

KOSE, R.; ARIF OZGUR, M.; ERBAS, O.; TUGCU, A. (2004) The analysis of wind data and wind energy potential in Kutahya, Turkey, Renewable and Sustainable Energy Reviews, v. 8, p. 277-288.
MUNN, R.E. (1969) Pollution wind-rose analysis. Atmósfera, v. 7 , p. 97-105.

SAHIN, B.; BILGILI, M.; AKILLI, H. (2005) The wind power potential of the eastern Mediterranean region of Turkey, Journal of Wind Engineering and Industrial Aerodynamics, v. 93, p. 171-183.

SILVA, F.B. \& SANTOS, I.A. (2006) Estudo do escoamento do vento da camada limite atmosférica na Zona Oeste do Rio de Janeiro utilizando o modelo RAMS. Anais XIII Congresso Brasileiro de Meteorologia, Fortaleza, CE.

TRUCCOLO, E.C. (2011) Assessment of the wind behavior in the northern coast of Santa Catarina. Revista Brasileira de Meteorologia, $v$. 26, n. 3, p. 451-460

UCAR, A. \& BALO, F. (2009) Evaluation of wind energy potential and electricity generation at six locations in Turkey, Applied Energy, v. 86, p. 1864-1872. 